\title{
Comprehensibility, manageability and meaningfulness at work: Construct validity of a scale measuring work- related sense of coherence
}

\begin{tabular}{|c|c|}
\hline \multicolumn{2}{|c|}{$\begin{array}{l}\text { Authors: } \\
\text { Katharina Vogt }{ }^{1} \\
\text { Gregor J. Jenny }{ }^{1,2} \\
\text { Georg F. Bauer }\end{array}$} \\
\hline \multicolumn{2}{|c|}{$\begin{array}{l}{ }^{1} \text { Public and Organizational } \\
\text { Health, Center for } \\
\text { Organizational and } \\
\text { Occupational Sciences, ETH } \\
\text { Zurich, Switzerland }\end{array}$} \\
\hline \multicolumn{2}{|c|}{$\begin{array}{l}{ }^{2} \text { Division Public and } \\
\text { Organizational Health, } \\
\text { Institute of Social and } \\
\text { Preventive Medicine, } \\
\text { University of Zurich, } \\
\text { Switzerland }\end{array}$} \\
\hline \multicolumn{2}{|c|}{$\begin{array}{l}\text { Correspondence to: } \\
\text { Katharina Vogt }\end{array}$} \\
\hline \multicolumn{2}{|c|}{$\begin{array}{l}\text { Email: } \\
\text { kvogt@ethz.ch }\end{array}$} \\
\hline \multicolumn{2}{|c|}{$\begin{array}{l}\text { Postal address: } \\
\text { Weinbergstrasse } 10 \\
\text { Zurich, Switzerland }\end{array}$} \\
\hline \multicolumn{2}{|c|}{$\begin{array}{l}\text { Dates: } \\
\text { Received: } 20 \text { Mar. } 2013 \\
\text { Accepted: } 05 \text { July } 2013 \\
\text { Published: } 16 \text { Sept. } 2013\end{array}$} \\
\hline \multicolumn{2}{|c|}{$\begin{array}{l}\text { How to cite this article: } \\
\text { Vogt, K., Jenny, G.J., } \\
\text { \& Bauer, G.F. (2013). } \\
\text { Comprehensibility, } \\
\text { manageability and } \\
\text { meaningfulness at work: } \\
\text { Construct validity of a } \\
\text { scale measuring work- } \\
\text { related sense of coherence. } \\
\text { SA Journal of Industrial } \\
\text { Psychology/SA Tydskrif vir } \\
\text { Bedryfsielkunde, 39(1), Art. } \\
\text { \#1111, 8 pages. http:// } \\
\text { dx.doi.org/10.4102/sajip. } \\
\text { v39i1.1111 }\end{array}$} \\
\hline \multicolumn{2}{|c|}{$\begin{array}{l}\text { Copyright: } \\
\text { (c) 2013. The Authors. } \\
\text { Licensee: AOSIS } \\
\text { OpenJournals. This work } \\
\text { is licensed under the } \\
\text { Creative Commons } \\
\text { Attribution License. }\end{array}$} \\
\hline \multicolumn{2}{|l|}{ Read online: } \\
\hline aripg & $\begin{array}{l}\text { Scan this QR } \\
\text { code with your } \\
\text { smart phone or } \\
\text { mobile device } \\
\text { to read online. }\end{array}$ \\
\hline
\end{tabular}

Authors:

Gregor J. Jenny ${ }^{1,2}$

Georg F. Bauer

Health, Center for

Organizational and

Occupational Sciences, ETH

2Division Public and

Organizational Health,

nstitute of Social and

University of Zurich,

Switzerland

\section{Correspondence to:}

Email:

sse 109,8092

Dates:

Accepted: 05 July 2013

meaningfulness at work:

Construct validity of a

related sense of coherence.

SA Journal of Industrial

Psychology/SA Tydskrif vir

dx.doi.org/10.4102/sajip.
Orientation: Work-related sense of coherence (Work-SoC) is defined as the perceived comprehensibility, manageability and meaningfulness of an individual's current work situation.

Research purpose: The aim of the present study was to investigate the factorial invariance and the construct validity of a scale that measures Work-SoC.

Motivation for the study: It might be useful to specifically apply the concept of sense of coherence to the work context.

Research design, approach and method: Statistical analysis was performed on crosssectional $(n=3412)$ and longitudinal $(n=1286)$ questionnaire data collected in eight medium to large Swiss companies from diverse economic sectors (four industrialproduction companies, one food-processing company, one public-administration service and two hospitals). The dataset therefore covers a broad range of different occupational groups.

Main findings: Multiple-group analyses indicated that the scale's factor structure remains invariant across different employee groups and across time. High values in job resources were related to high values in Work-SoC whereas high values in job demands were related to low values in Work-SoC. Furthermore, Work-SoC acted as a partial mediator between job resources and work engagement.

Practical/managerial implications: It can be concluded that Work-SoC might serve as a practical screening instrument for assessing an employee's perception of the potential health-promoting qualities of his or her current work situation.

Contribution/value-add: The study advances both the salutogenic theory and the field of positive occupational health psychology by redefining sense of coherence as an interactional and context-specific construct that is useful for intervention research.

\section{Introduction}

Sense of coherence $(\mathrm{SoC})$ is defined as a global and nonspecific orientation that captures an individual's perception of life as being comprehensible, manageable and meaningful (Antonovsky, 1987b). It has been consistently found that individuals with a strong SoC are healthier than those with a weak SoC (Eriksson \& Lindström, 2006), making this an interesting concept for those concerned with health and its promotion.

However, since general SoC is primarily formed during early life and is also influenced by life experiences outside work (Antonovsky, 1987b), a more context-specific definition of SoC might be useful for the planning and evaluation of health-related interventions in the workplace. The central aim of this article is therefore to introduce the concept of work-related sense of coherence (Work-SoC) and to investigate the factorial invariance and construct validity of a newly developed scale measuring Work-SoC.

In the first section below, an overview of the literature on SoC in the context of work will be provided. Then a number of context-specific applications of SoC will be discussed, and the concept of Work-SoC will be introduced. In the second section, the research design is presented, which is followed by a section on the results concerning the factorial invariance and the construct validity of a scale measuring Work-SoC. In the last section, the results and their implications are discussed. 


\section{Literature review}

\section{Sense of coherence in the context of work}

A number of studies examined SoC in the context of work. Feldt (1997) reports that technical designers with a high level of SoC experience fewer psychosomatic symptoms and less emotional exhaustion. Furthermore, some support was found for a moderating effect, suggesting that those employees with higher levels of SoC cope more efficiently with work stressors than those with lower levels of SoC. In line with this, Albertsen, Nielsen and Borg (2001) report that employees with a strong SoC experience fewer stress symptoms and cope more efficiently with strain in the work environment. Similar results are reported by Kinman (2008), who found that academic employees with a stronger SoC tend to be in better physical and psychological health than those with a weaker SoC. Moreover, she reports that employees with a strong SoC might be protected from the negative impact of some job-related stressors such as high work-home interface demands. Longitudinal analyses show that a high level of SoC might decrease the risk of developing burnout symptoms 10 years later (Kalimo, Pahkin, Mutanen \& Toppinen-Tanner, 2003) and that SoC might protect against the negative effects of organisational change on mental health (Pahkin, Väänänen, Koskinen, Bergbom \& Kouvonen, 2011). Van der Colff and Rothmann (2009) report that SoC is not only related to lower levels of exhaustion but also to higher levels of positive outcomes such as work engagement. These authors reason that employees with a high SoC are more likely to perceive their environment in a positive and coherent way and use approach coping strategies rather than avoidance coping strategies. These results are complemented by a study by Muller and Rothmann (2009), who performed a content analysis of written replies from 600 employees and found that their perception of helping factors and restraining factors differed depending on their SoC level. Individuals with a high SoC might also have an increased ability to change their work characteristics in a favourable way, as reported in a three-year follow-up study by Feldt, Kivimäki, Rantala and Tolvanen (2004).

These results suggest that SoC plays an important role in the health-related effects of working conditions, that it might influence perception and coping mechanisms and that it might act as a predictor of work characteristics. However, it could also be argued that work affects the SoC of employees. Feldt, Kinnunen and Mauno (2000) conducted a one-year follow-up study and found that SoC partly mediates the relationship between a good organisational climate and well-being and between low job insecurity and well-being. Furthermore, changes in organisational climate and leadership relations were associated with changes in SoC. Similarly, the studies by Albertsen et al. (2001) and Hogh and Mikkelsen (2005) both report that SoC partly explains the relationship between work environment and stress symptoms.

The idea that working conditions might influence SoC is in line with Antonovsky's (1987a, 1987b) suggestion that the concept of SoC can provide a theoretical model for the analysis of working conditions. He states that the working environment is decisive in shaping the SoC of an individual employee and therefore plays an important role in the formation of health in one's adult life.

\section{Context-specific sense of coherence}

Several authors redefined SoC as a flexible and contextspecific construct. Artinian (1997) introduced situational SoC, which is a construct that reflects an individual's present and specific orientation rather than a global life orientation. Situational SoC was applied in a hospital setting to measure clients' responses to stressful situations. Antonovsky and Sourani (1988) discuss the construct of family SoC, which describes the perceived coherence of family life. Following the idea of a more specific concept of SoC, Gräser (2003) constructed a 13-item scale measuring university SoC and investigated to what extent university staff perceives their work situation as coherent. The scale has a good reliability and negatively correlates with health-related problems. Gräser (2003) suggests that university SoC can be used to measure the health-promoting quality of a university.

\section{The concept of a work-related sense of coherence}

In similar vein, Bauer and Jenny (2007) proposed the concept of a work-related SoC (Work-SoC). To further refine this concept, this article defines Work-SoC as the perceived comprehensibility, manageability and meaningfulness of an individual's current work situation. In line with the concept of general SoC (Antonovsky, 1987b), 'comprehensibility' describes the extent to which a work situation is perceived as structured, consistent and clear; 'manageability' describes the extent to which an employee perceives that adequate resources are available to cope with the demands in the workplace and 'meaningfulness' describes the extent to which a situation at work is seen as worthy of commitment and involvement. This perception of comprehensibility, manageability and meaningfulness is influenced by the interaction between individual characteristics (an employee's personality and experiences) and the characteristics of the working environment (work-related structures and processes).

This interactional definition of Work-SoC is in line with related interactional concepts such as the conceptualisation of salutogenesis in which the development of SoC is influenced by both stressors and general resistance resources (Antonovsky, 1979), the transactional model of stress (Lazarus \& Folkman, 1984), the health-development model (Bauer, Davies \& Pelikan, 2006) and the personenvironment-fit model (Edwards \& Shipp, 2007). In addition, the job demands-resources (JD-R) model considers perceived job demands and job resources to be influenced by both personal and organisational factors (Dollard \& Bakker, 2010; Xanthopoulou, Bakker, Demerouti \& Schaufeli, 2007).

Referring to the original conceptualisation of Bauer and Jenny (2007), Eberz, Becker and Antony (2011) re-interpreted work- 
related sense of coherence as an individual meta-resource that acts as a moderator of the work-health relationship by reducing the potential negative effects of work stressors. Their initial exploratory study with a homogeneous group of 93 pastor's secretaries indicates that - unlike general SoC Work-SoC explains incremental variance and appears to be a stronger predictor of work-related stress. The authors further state that the health-promoting effect of social support can be explained by the mediating role of Work-SoC.

Building on the original conceptualisation of Work-SoC as an interactional construct, Vogt, Jenny, Füllemann, Inauen and Bauer (2012) report that a nine-item questionnaire measuring the comprehensibility, manageability and meaningfulness of work has a good internal consistency (Cronbach alpha = 0.83 ) and that the scale has a three-factor structure with the sub-dimensions of comprehensibility, manageability and meaningfulness.

\section{The present study}

The present study operationalises the interactional concept of Work-SoC as a context-specific construct that is more dynamic and sensitive to changes than general SoC. Workrelated sense of coherence might therefore be used as an indicator of the perceived health-promoting quality of an individual's working conditions. However, if the Work-SoC scale is to be applied in broad employee surveys, it should be determined whether the three-factor structure is invariant across different groups. Furthermore, for the scale to be used in longitudinal analyses, it is also important to establish whether the scale shows factorial invariance across time. Therefore, the following hypothesis was tested:

Hypothesis 1: The correlated three-factor structure of WorkSoC is invariant across groups and time.

Hypothesis 2 and Hypothesis 3 concern the construct validity of the Work-SoC scale. As Work-SoC is defined as the perceived comprehensibility, manageability and meaningfulness of an individual's current work situation, it is expected that Work-SoC is related to the health-relevant measures of the current work situation, which are operationalised through job demands and job resources (JD-R), as in the JD-R model (Bakker \& Demerouti, 2007). In relation to that model, it was hypothesised that positively valued work characteristics (e.g. job resources) would be positively related to Work-SoC, that is, the comprehensibility, manageability and meaningfulness of an individual's current work situation. Negatively valued work characteristics (e.g. job demands), in contrast, were hypothesised to be negatively related to Work-SoC.

Hypothesis 2: (a) Job resources are related to higher values in Work-SoC, and (b) job demands are related to lower values in Work-SoC.

The relationship between job resources and work engagement and between job demands and exhaustion has been argued in research on the JD-R model (Bakker \& Demerouti, 2007).
Based on the finding that SoC partly mediates the relationship between job characteristics and well-being (Albertsen et al., 2001; Feldt et al., 2000, Hogh \& Mikkelsen, 2005) and in line with the JD-R model, it was hypothesised that Work-SoC acts as a partial mediator in the relationship between job resources and work engagement as well as between job demands and exhaustion, respectively.

Hypothesis 3: (a) Work-SoC partially mediates the relationship between job resources and work engagement, and secondly, (b) Work-SoC partially mediates the relationship between job demands and exhaustion.

Contrary to the relatively stable general SoC, Work-SoC is expected to vary when work characteristics (e.g. the job demands and job resources) change. It was therefore hypothesised that Work-SoC does not mediate the longitudinal relationship between job resources and work engagement and between job demands and exhaustion.

Hypothesis 3: (c) Work-SoC at baseline does not mediate the relationship between job resources at baseline and work engagement at the first follow-up (longitudinal), and (d) Work-SoC at baseline does not mediate the relationship between job demands at baseline and exhaustion at the first follow-up (longitudinal).

\section{Research design Research approach}

A quantitative data analysis of a large dataset with three measurement points was undertaken to investigate the factorial invariance and the construct validity of the WorkSoC scale.

\section{Research method Research participants}

The present study investigated cross-sectional and longitudinal data collected in eight medium to large Swiss companies. The baseline survey (T1) yielded a sample of 3412 participants (response rate: 68.6\%). At the first followup after one year (T2), 3085 employees participated in the study (response rate: $60.5 \%$ ). At the second follow-up after two years (T3), 2395 employees participated in the study (response rate: $48.2 \%$ ).

The survey contains data from employees working in diverse economic sectors (four industrial-production companies, one food-processing company, one public-administration service and two hospitals) and therefore covers a broad range of different occupational groups (e.g. manufacturing, maintenance, mechanical work, administration, service sector, health professionals and cleaning and kitchen staff). At the baseline survey, the sample consisted of $40.7 \%$ females, the average age was 38.9 years $(S D=11.5)$ and $24.8 \%$ of respondents had a leadership position. Furthermore, 78.2\% of respondents worked full time, the mean organisational tenure was 8.6 years $(\mathrm{SD}=9.3)$ and the mean job tenure 
was 5.3 years $(\mathrm{SD}=6.6)$. At the first follow-up, $71.2 \%$ of the participants answered the survey in German, $25.5 \%$ in French and 3.3\% in other languages such as English, Italian, or Serbo-Croatian (no data are available on the language versions of the baseline survey). The participation in the survey was voluntary.

\section{Measuring instruments}

Work-related sense of coherence: Work-SoC was assessed using a nine-item scale (see Figure 1). The scale has a Cronbach alpha of .83. Items 1, 3, 6 and 9 measured the sub-dimension of comprehensibility whilst items 4 and 7 measured the subdimension of manageability and items 2, 5 and 8 measured the sub-dimension of meaningfulness.

Work engagement: Work engagement was assessed using the nine-item version of the Utrecht Work Engagement Scale (Schaufeli, Bakker \& Salanova, 2006). This scale measures the underlying dimensions of work engagement, including vigour (e.g. 'At work, I feel like I am bursting with energy'), dedication (e.g. 'I am enthusiastic about my job') and absorption (e.g. 'I am immersed in my work'). The items were scored on a 7-point scale, ranging from 0 (Never) to 6 (Always/every day). The scale has a Cronbach alpha of 0.95 .

Exhaustion: Exhaustion was assessed using one dimension of the Oldenburg Burnout Inventory (Demerouti, 1999). The exhaustion scale contains eight items (e.g. 'After my work, I usually feel worn out and weary'). The items were scored on a four-point scale, ranging from 1 (Totally disagree) to 4 (Totally agree). The scale has a Cronbach alpha of 0.80 .

Job resources: Five job resources that are present across various jobs and organisations were measured. Task identity was assessed by a single item (e.g. 'In my job, one can produce something or carry out an assignment from $A$ to $Z^{\prime}$ ). The item was scored on a five-point scale ranging from 1 (almost never/not at all true) to 5 (almost always/fully true) (Udris \& Rimann, 1999). Job control was assessed with a six-item scale (e.g. 'Can you organise your workday autonomously?'). The items were scored on a five-point scale ranging from 1 (very little/not at all) to 5 (very much) (Semmer, Zapf \& Dunckel, 1999). The scale has a Cronbach alpha of 0.87. Social support was assessed using three items. Participants were asked how much they could rely on their direct supervisor, on their closest colleagues and on other colleagues in difficult situations at work. The items were scored on a fivepoint scale, ranging from 1 (very little/not at all) to 5 (very much) (Frese, 1989). The scale has a Cronbach alpha of 0.70 .

\begin{tabular}{|c|c|c|c|c|c|c|c|c|c|}
\hline \multicolumn{10}{|c|}{ How do you personally find your current job and work situation in general? } \\
\hline $1 r$ & manageable & o & 0 & 0 & 0 & 0 & 0 & o & unmanageable \\
\hline 2 & meaningless & ○ & ० & ○ & $\circ$ & ० & ○ & ○ & meaningful \\
\hline $3 r$ & structured & ० & ० & $\circ$ & ○ & ० & ○ & ○ & unstructured \\
\hline $4 r$ & $\begin{array}{l}\text { easy to } \\
\text { influence }\end{array}$ & ○ & ○ & $\circ$ & ○ & ○ & ○ & ○ & $\begin{array}{l}\text { impossible to } \\
\text { influence }\end{array}$ \\
\hline 5 & insignificant & ○ & 0 & ० & $\circ$ & 0 & $\circ$ & ० & significant \\
\hline $6 r$ & clear & ० & ० & ○ & ० & o & o & ० & unclear \\
\hline $7 r$ & controllable & ० & ० & $\circ$ & ○ & ० & ० & ○ & uncontrollable \\
\hline 8 & unrewarding & 0 & 0 & 0 & $\circ$ & 0 & 0 & $\circ$ & rewarding \\
\hline $9 r$ & predictable & 0 & 0 & 0 & 0 & 0 & 0 & 0 & unpredictable \\
\hline
\end{tabular}

FIGURE 1: The Work-SoC Questionnaire.
Appreciation was assessed with two items (e.g. 'Overall, how satisfied are you with your colleagues' appreciation of you as a person?' and 'Overall, how satisfied are you with your line manager's appreciation of you as a person?'). The items were scored on a seven-point graphical scale with smiley faces from 1 (extremely dissatisfied) to 7 (extremely satisfied) (Jacobshagen, Oehler, Stettler, Liechti \& Semmer, 2008). The scale has a Cronbach alpha of 0.59. Interpersonal justice was assessed using four items (e.g. 'To what extent has he or she treated you with respect?'). The items were scored on a fivepoint scale, ranging from 1 (to a small extent) to 5 (to a large extent) (Colquitt, 2001). The scale has a Cronbach alpha of 0.82 .

Job demands: Four job demands that are relevant in a number of work environments were measured. Time pressure (e.g. 'At work, how often is a rapid pace of work required?') and work interruption (e.g. 'How often does it occur that you cannot work on something in peace because something else always comes in between?') were both assessed with four items that were scored on a five-point scale ranging from 1 (very rarely/never) to 5 (very often/constantly) (Semmer, Zapf \& Dunckel, 1995). The Cronbach alpha for time pressure is 0.82 , and the Cronbach alpha for work interruption is 0.83 . Qualitative overload was assessed using three items (e.g. 'It happens that work is too difficult'). The items were scored on a five-point scale ranging from 1 (almost never/not at all true) to 5 (Almost always / fully true) (Udris \& Rimann, 1999). The scale has a Cronbach alpha of 0.77. Uncertainty at work was assessed using four items (e.g. 'How often do you receive contradictory instructions from different supervisors?'). Three items were rated on a five-point scale ranging from 1 (very rarely/never) to 5 (very often/constantly), and one item was rated on a five-point scale ranging from 1 (from nobody) to 5 (from more than three persons) (Semmer et al., 1995). The scale has a Cronbach alpha of 0.69 .

\section{Research procedure}

Participants voluntarily filled in an online questionnaire during working hours and were assured of anonymity and the confidentiality of the data. The three measurement points were linked with an anonymous code for each participant.

\section{Statistical analysis}

The factorial invariance of Work-SoC across different groups and time (Hypothesis 1) was tested using multiple group analysis (Byrne, 2004; 2010) with the AMOS 20 software package. In this procedure, a fully constrained model (with equality constraints on all factor loadings, factor variances and factor co-variances) was compared to a default model without cross-group constraints. Traditionally, $\chi^{2}$ difference tests are used to assess whether there is a significant difference between the models (Schmitt \& Kuljanin, 2008). However, because $\chi^{2}$ is highly dependent on sample size, invariance decisions were based on the difference in the comparative fit index (CFI) and the difference in root mean square error of approximation (RMSEA) with a $\Delta$ CFI $\geq 0.01$ supplemented by a $\Delta$ RMSEA $\geq 0.015$ indicating non-invariance (Chen, 2007; Cheung \& Rensvold, 2002). 
For the use in the correlation (Hypothesis 2) and regression analyses (Hypothesis 3), factor scores for the job demands and job resources were calculated with the regression method. To test the mediating role of Work-SoC (Hypothesis 3), the SPSS macro provided by Preacher and Hayes (2008) was used.

\section{Results}

\section{Invariance tests}

The invariance tests of Work-SoC across different groups and across time are presented in Table 1 . The results indicate that the scale's factor structure is invariant across gender, different age groups, employees with lower and higher levels of education and employees with or without a leadership position. Furthermore, the factor structure of Work-SoC is invariant across three measurement points

\section{Relationship between job resources, job demands and the work-related sense of coherence}

The cross-sectional and longitudinal correlations of the investigated constructs are presented in Table 2. Job resources were found to be positively correlated to Work-SoC ( $r=0.44$; $p<0.001)$, and job demands were found to be negatively correlated to Work-SoC $(r=-0.37 ; p<0.001)$.

\section{Work-related sense of coherence as a partial mediator between job resources and work engagement}

Table 3 reports the results of the cross-sectional and longitudinal mediation analyses on the relationship between job resources and work engagement. In line with the

TABLE 1: Invariance of Work-SoC across different groups and time.

\begin{tabular}{|c|c|c|c|c|c|c|c|c|c|c|c|c|c|}
\hline \multirow[t]{2}{*}{ Model } & \multirow[t]{2}{*}{$N$} & \multicolumn{4}{|c|}{ Unconstrained } & \multicolumn{8}{|c|}{ Fully constrained } \\
\hline & & $\chi^{2}$ & $d f$ & CFI & RMSEA & $\chi^{2}$ & $d f$ & $\chi_{\text {diff }}^{2}$ & $\mathbf{d f}_{\text {diff }}$ & CFI & $\mathrm{CFI}_{\text {diff }}$ & RMSEA & RMSEA $_{\text {diff }}$ \\
\hline 1. Gender & - & 348.8 & 48 & 0.966 & 0.046 & 429 & 60 & $80.2^{* *}$ & 12 & 0.958 & 0.008 & 0.046 & 0 \\
\hline Male & 1762 & - & - & - & - & - & - & - & - & - & - & - & - \\
\hline Female & 1205 & - & - & - & - & - & - & - & - & - & - & - & - \\
\hline 2. Age groups & - & 418.9 & 72 & 0.966 & 0.037 & 482.6 & 96 & $63.7 * *$ & 24 & 0.962 & 0.004 & 0.034 & 0.003 \\
\hline below 25 & 351 & - & - & - & - & - & - & - & - & - & - & - & - \\
\hline above 50 & 764 & & & & & & & & & & & & \\
\hline $\begin{array}{l}\text { 3. Lower and higher } \\
\text { Education }\end{array}$ & - & 411.9 & 48 & 0.965 & 0.046 & 452.4 & 60 & $40.5^{* *}$ & 12 & 0.962 & 0.003 & 0.043 & 0.003 \\
\hline lower & 1868 & - & - & - & - & - & & - & - & - & - & - & - \\
\hline higher & 1647 & - & - & - & - & - & - & - & - & - & - & - & - \\
\hline $\begin{array}{l}\text { 4. With and without leadership } \\
\text { position }\end{array}$ & - & 388.4 & 48 & 0.967 & 0.045 & 449 & 60 & $60.6^{* *}$ & 12 & 0.962 & 0.005 & 0.043 & 0.002 \\
\hline with & 879 & - & - & - & - & - & - & - & - & - & - & - & - \\
\hline 5. Three measurement points & - & 872.3 & 72 & 0.97 & 0.035 & 960.9 & 96 & $88.6^{* *}$ & 24 & 0.968 & 0.002 & 0.032 & 0.003 \\
\hline baseline survey & 3227 & - & - & - & - & - & - & - & - & - & - & - & - \\
\hline first follow-up & 3042 & - & - & - & - & - & - & - & - & - & - & - & - \\
\hline second follow-up & 2393 & - & & - & - & - & - & - & - & - & - & - & - \\
\hline
\end{tabular}

$\chi^{2}$, chi-square statistic; $d f$, degrees of freedom; CFI, Comparative Fit Index; $\mathrm{CFI}_{\text {diff }}$ difference in Comparative Fit Index; RMSEA, root mean square error of approximation; $\chi_{\text {diff }}^{2}$ difference in chi-square statistic; $d f_{\text {diff }}$ difference in degrees of freedom; RMSEA $_{\text {ditf }}$ difference in root mean square error of approximation.

Fully constrained refers to: equality constraints on all factor loadings, factor variances and factor covariances.

${ }_{* *}^{*}, p<0.01$.

TABLE 2: Inter-correlations of the studied variables ( $N=1233$ to 3639$)$.

\begin{tabular}{|c|c|c|c|c|c|c|c|c|c|c|c|}
\hline Variables & 1 & 2 & 3 & 4 & 5 & 6 & 7 & 8 & 9 & 10 & 11 \\
\hline 1. Age & - & - & - & - & - & - & - & - & - & - & - \\
\hline 2. Education & -.03 & - & - & - & - & - & - & - & - & - & - \\
\hline 3. Work-SoC T1 & $.15^{* *}$ & .00 & - & - & - & - & - & - & - & - & - \\
\hline 4. Job resources T1 & .01 & $.16^{* *}$ & $.44^{* *}$ & - & - & - & - & - & - & - & - \\
\hline 5. Job demands T1 & .03 & $.24^{* *}$ & $-.37^{* *}$ & $-.22^{* *}$ & - & - & - & - & - & - & - \\
\hline 6. Work engagement T1 & $.14^{* *}$ & .03 & $.49^{* *}$ & $.33^{* *}$ & $-.08^{* *}$ & - & - & - & - & - & - \\
\hline 8. Work-SoCT2 & $.20^{* *}$ & .01 & $.53^{* *}$ & $.34^{* *}$ & $-.23^{* *}$ & $.34^{* *}$ & $-.32^{* *}$ & - & - & - & - \\
\hline 9. Job resources $\mathrm{T} 2$ & $.05^{*}$ & $.15^{* *}$ & $.33^{* *}$ & $.62^{* *}$ & $-.15^{* *}$ & $.22^{* *}$ & $-.27^{* *}$ & $.52^{* *}$ & & - & - \\
\hline 10. Job demands $T 2$ & $-.06^{*}$ & $.20^{* *}$ & $-.32^{* *}$ & $-.19^{* *}$ & $.67^{* *}$ & $-.09^{* *}$ & $.31^{* *}$ & $-.41^{* *}$ & $-.27^{* *}$ & - & - \\
\hline 11. Work engagement $\mathrm{T} 2$ & $.16^{* *}$ & -.03 & $.36^{* *}$ & $.21^{* *}$ & $-.09^{* *}$ & $.66^{* *}$ & $-.30^{* *}$ & $.51^{* *}$ & $.37^{* *}$ & $-.20^{* *}$ & - \\
\hline 12. Exhaustion $\mathrm{T} 2$ & $-.15^{* *}$ & .00 & $-.32^{* *}$ & $-.26^{* *}$ & $.30^{* *}$ & $-.27^{* *}$ & $.59^{* *}$ & $-.47^{* *}$ & $-.39^{* *}$ & $.46^{* *}$ & $-.42^{* *}$ \\
\hline
\end{tabular}

Work-SoC, work-related sense of coherence; T1; baseline survey; T2; first follow-up.

$*, p<0.05 ;{ }^{* *} p<0.01$. 
TABLE 3: Mediation analyses of job resources on work engagement via workrelated sense of coherence.

\begin{tabular}{|c|c|c|c|c|c|c|}
\hline \multirow[t]{2}{*}{ Variable } & \multicolumn{3}{|c|}{$\begin{array}{c}\text { Cross-Sectional T1 } \\
(N=1993)\end{array}$} & \multicolumn{3}{|c|}{$\begin{array}{c}\text { Longitudinal T2 } \\
\quad(N=1218)\end{array}$} \\
\hline & B & SE B & $p$ & B & SE B & $p$ \\
\hline \multicolumn{7}{|l|}{ Control variables } \\
\hline Gender & .12 & .05 & .015 & .01 & .05 & .80 \\
\hline Age & .01 & .00 & $<.001$ & .01 & .00 & $<.001$ \\
\hline Education & -.01 & .02 & .74 & -.07 & .02 & .003 \\
\hline $\begin{array}{l}\text { Work Engagement } \\
\text { T1 }\end{array}$ & - & - & - & .64 & .02 & $<.001$ \\
\hline Job resources c' & .15 & .03 & $<.001$ & .01 & .03 & .65 \\
\hline (Total effect c) & .42 & .03 & $<.001$ & .03 & .03 & .24 \\
\hline \multicolumn{7}{|l|}{ Indirect effect } \\
\hline Work-SoC & .27 & .02 & {$\left[.23 ; .31^{\dagger}\right]$} & .02 & .01 & {$\left[-.01 ; .05^{\dagger}\right]$} \\
\hline$R^{2}$ & .27 & & $<.001$ & .46 & & $<.001$ \\
\hline
\end{tabular}

$\mathrm{B}$, regression coefficient; $\mathrm{SE} \mathrm{B}$, standard error of regression coefficient; $p$, probability value $\mathrm{T} 1$, baseline survey; T2, first follow-up; Work-SoC, work-related sense of coherence; $R^{2}$ proportion variance explained.

Number of bootstrap resamples: 5000

bias corrected confidence interval 95\%.

TABLE 4: Mediation analyses of job demands on exhaustion via work-related sense of coherence.

\begin{tabular}{|c|c|c|c|c|c|c|}
\hline \multirow[t]{2}{*}{ Variable } & \multicolumn{3}{|c|}{$\begin{array}{c}\text { Cross-Sectional T1 } \\
\quad(N=\mathbf{2 9 1 1 )}\end{array}$} & \multicolumn{3}{|c|}{$\begin{array}{l}\text { Longitudinal T2 } \\
\quad(N=1657)\end{array}$} \\
\hline & B & SE B & $p$ & B & SE B & $p$ \\
\hline \multicolumn{7}{|l|}{ Control variables } \\
\hline Gender & .01 & .02 & .75 & -.04 & .02 & .039 \\
\hline Age & .00 & .00 & $<.001$ & .00 & .00 & $<.001$ \\
\hline Education & -.03 & .01 & $<.001$ & .00 & .01 & .95 \\
\hline Exhaustion T1 & - & - & - & .56 & .02 & $<.001$ \\
\hline Job demands $c^{\prime}$ & .18 & .01 & $<.001$ & .03 & .01 & .015 \\
\hline (Total effect c) & .25 & .01 & $<.001$ & .04 & .01 & .004 \\
\hline \multicolumn{7}{|l|}{ Indirect effect } \\
\hline Work-SoC & .07 & .00 & {$\left[.06 ; .08^{\dagger}\right]$} & .01 & .00 & {$\left[-.00 ; .01^{\dagger}\right]$} \\
\hline$R^{2}$ & .30 & - & $<.001$ & - & .37 & $<.001$ \\
\hline
\end{tabular}

$\mathrm{B}$, regression coefficient SE B, standard error of regression coefficient; $p$, probability value T1, baseline survey; T2, first follow-up.

Number of bootstrap resamples: 5000

$\dagger$, bias corrected confidence interval $95 \%$.

literature on the JD-R model (Bakker \& Demerouti, 2007), job resources have a significant effect on work engagement (see Table 3, total effect c). The effect decreases in size but remains significant when Work-SoC is taken into account (effect of job resources c'), which indicates partial mediation. The bootstrapped indirect effect via Work-SoC is significant $(\mathrm{B}=0.27)$. In the longitudinal model, no direct or indirect effect of job resources $\mathrm{T} 1$ and Work-SoC $\mathrm{T} 1$ on work engagement $\mathrm{T} 2$ was found when controlling for work engagement T1.

\section{Work-related sense of coherence as a partial mediator between job demands and exhaustion}

Table 4 reports the results of the cross-sectional and longitudinal mediation analyses on the relationship between job demands and exhaustion. A significant cross-sectional effect of job demands on exhaustion (see Table 4, total effect c) was found. The effect decreases in size but remains significant when Work-SoC is taken into account (effect of job demands $c^{\prime}$ ). The bootstrapped indirect effect via Work-SoC was significant $(\mathrm{B}=0.07)$. In the longitudinal model, the total effect of job demands $\mathrm{T} 1$ on exhaustion $\mathrm{T} 2$ was significant $(B=0.04)$. No indirect effect of Work-SoC was found in the longitudinal model.

\section{Discussion}

This article reported on an investigation into the factorial invariance and the construct validity of a scale measuring Work-SoC. Multiple group analyses indicate that the scale functions equally well across different employee groups and that the scale's factor structure is invariant across time. High values in job resources are related to high values in WorkSoC whereas high values in job demands are related to low values in Work-SoC. In the cross-sectional analyses, WorkSoC was found to be a partial mediator of the relationship between job resources and work engagement and between job demands and exhaustion. No mediating effect of WorkSoC was found in the longitudinal analyses.

According to Byrne (2004), it is important to assess that a construct has the same theoretical structure for each group studied and to test for multiple group invariance. This study shows that the three-factor structure of Work-SoC reported by Vogt et al. (2012) is invariant across gender, different age groups, employees with lower and higher levels of education, employees with or without leaderships positions and time. These results provide evidence for the robustness of the Work-SoC scale as they suggest that changes or differences in Work-SoC can be attributed to changes or differences in the actual values of Work-SoC but not to changes or differences in the structure or measurement of the construct.

Based on the assumption that job resources and job demands are both related to the comprehensibility, manageability and meaningfulness of an individual's current work situation, the hypotheses that job resources are related to higher values in Work-SoC and that job demands are related to lower values in Work-SoC have been tested and found to be true. Therefore, it can be concluded that Work-SoC partly reflects an individual's job resources and job demands. This is in line with the conceptualisation of Work-SoC as an interactional construct that is partly formed by environmental factors in the workplace.

The mediating effect of Work-SoC is considerably stronger in the process that leads from job resources to work engagement than it is in the process that leads from job demands to exhaustion. This is consistent with the conceptualisation of SoC as a health resource. Its theoretical background in the field of Salutogenesis emphasises the promotion of health, rather than focusing on factors that cause diseases (Antonovsky, 1987b). Therefore, one could conclude that positively valued work characteristics such as task identity, job control and social support affect employee well-being both indirectly through Work-SoC and directly as only partial mediation was found. Given the mediating role of Work-SoC between job resources and work engagement and 
between job demands and exhaustion, one could further conclude that Work-SoC might indeed serve as an indicator of an individual's perception of the health-promoting quality of the working situation. In line with expectations, no mediating effect of Work-SoC in the longitudinal data was found. Rather, the effect of the control variable baseline-work engagement on the outcome variable work engagement at the first follow up after one year (or baseline exhaustion on exhaustion at the first follow-up) was so strong that all other effects were diminished.

\section{Limitations of the study and further research}

The present study has some limitations that should be considered. As all of the investigated measures were selfreported, common method biases may have influenced our results; therefore, the relationships that were found might be lower if measured differently (Podsakoff, MacKenzie, Lee \& Podsakoff, 2003). Furthermore, 'task identity' was measured with a single item only. However, as this measure was aggregated to a job-resources factor, this should not pose a major problem regarding the interpretation of the study's results. As a mediating effect of Work-SoC was found in the cross-sectional data only, no conclusions regarding the causality and direction of this mediation can be drawn. Further, the mechanisms underlying these relationships can only be speculated.

Using Work-SoC as an indicator of the overall quality of working life presupposes that Work-SoC is sensitive to changing working conditions. As proposed by Eberz et al. (2011), further research might investigate whether changes in an individual's work situation lead to changes in WorkSoC and whether these changes are larger than changes in the general SoC. Longitudinal data with short intervals (e.g. a daily-diary method) might be particularly appropriate for a detailed examination of Work-SoC and its relation to work characteristics and health-related outcomes. This methodology might also provide information on how the Work-SoC of individual employees could be enhanced (Kalimo et al., 2003).

\section{Conclusion}

Even with the above-mentioned limitations in mind, the present study has investigated longitudinal data of a large sample and has provided interesting and relevant results concerning the factorial invariance and the construct validity of the Work-SoC scale. General SoC has been studied in a number of South African studies (e.g. Muller \& Rothmann, 2009; Van der Colff \& Rothmann, 2009), and the present study adds to this discourse by introducing an innovative, context-specific conceptualisation of SoC.

A practical application of Work-SoC might be its use as an economic means of assessing the perception of the potential health-promoting quality of an individual's current work situation. Work-SoC might be used as a screening instrument to detect the need for further investigation and to derive interventions that enhance the health-promoting quality of working environments. In line with a call for positive health (Seligman, 2008), the construct of Work-SoC emphasises a resource-oriented view on workplace health promotion.

\section{Acknowledgements Competing interests}

The authors declare that they have no financial or personal relationship(s) which may have inappropriately influenced them in writing this article.

\section{Authors' contributions}

K.V. (ETH Zurich) drafted the article and analysed the data. G.J.J. (ETH Zurich and University of Zurich) and G.F.B (ETH Zurich and University of Zurich) supervised the writing of the article and the statistical analyses. All authors were responsible for the conception and design of the study. Each made significant contributions to the discussion and interpretation of the results and read and approved the final manuscript. G.J.J. (ETH Zurich and University of Zurich) and G.F.B (ETH Zurich and University of Zurich) were responsible for the collection of data for the study. G.F.B. (ETH Zurich and University of Zurich) was responsible for securing funding for the study.

\section{References}

Albertsen, K., Nielsen, M.L., \& Borg, V. (2001). The Danish psychosocial work environment and symptoms of stress: The main, mediating and moderating role of sense of coherence. Work \& Stress, 15, 241-253. http://dx.doi. org/10.1080/02678370110066562

Antonovsky, A. (1979). Health, stress, and coping. San Francisco, CA: Jossey-Bass.

Antonovsky, A. (1987a). Health promoting factors at work: The sense of coherence. In R. Kalimo, M.A. El-Batawi, \& C.L. Cooper (Eds.), Psychosocial factors at work and their relation to health (pp. 153-167). Geneva, Switzerland: World Health and their relation

Antonovsky, A. (1987b). Unraveling the mystery of health: How people manage stress and stay well. San Francisco, CA: Jossey-Bass.

Antonovsky, A., \& Sourani, T. (1988). Family sense of coherence and family adaptation. Journal of Marriage and the Family, 50, 79-92. http://dx.doi.org/10.2307/352429

Artinian, B.M. (1997). Situational sense of coherence: Development and measurement of the construct. In B.M. Artinian \& M.M. Conger (Eds.), The intersystem model: Integrating theory and practice (pp. 18-30). Thousand Oaks, CA: Sage.

Bakker, A.B., \& Demerouti, E. (2007). The job demands-resources model: State of the art. Journal of Managerial Psychology, 22, 309-328. http://dx.doi. org/10.1108/02683940710733115

Bauer, G., Davies, J.K., \& Pelikan, J. (2006). The EUHPID health development model for the classification of public health indicators. Health Promotion International, 21, 153-159.

Bauer, G., \& Jenny, G. (2007). Development, implementation and dissemination of occupational health management (OHM): Putting salutogenesis into practice. In S. McIntyre \& J. Houdmont (Eds.), Occupational health psychology: European perspectives on research, education and practice (pp. 219-250). Castelo da Maia, Portugal: ISMAI.

Byrne, B.M. (2004). Testing for multigroup invariance using AMOS graphics: A road less traveled. Structural Equation Modeling, 11, 272-300. http://dx.doi.org/10.1207/ s15328007sem1102_8

Byrne, B.M. (2010). Structural equation modeling with AMOS: Basic concepts, applications, and programming. New York, NY: Routledge.

Chen, F.F. (2007). Sensitivity of goodness of fit indexes to lack of measurement invariance. Structural Equation Modeling, 14, 464-504. http://dx.doi. org/10.1080/10705510701301834

Cheung, G.W., \& Rensvold, R.B. (2002). Evaluating goodness-of-fit indexes for testing measurement invariance. Structural Equation Modeling, 9, 233-255. http:// dx.doi.org/10.1207/S15328007SEM0902_5

Colquitt, J.A. (2001). On the dimensionality of organizational justice: A construct validation of a measure. Journal of Applied Psychology, 86, 386-400. http:// dx.doi.org/10.1037//0021-9010.86.3.386

Demerouti, E. (1999). Burnout: Eine Folge konkreter Arbeitsbedingungen bei Dienstleistungs- und Produktionstätigkeiten. Frankfurt, Germany: Lang. 
Dollard, M.F., \& Bakker, A.B. (2010). Psychosocial safety climate as a precursor to conducive work environments, psychological health problems, and employee engagement. Journal of Occupational and Organizational Psychology, 83, 579engagement. Journal of Occupational and Organiza
599. http://dx.doi.org/10.1348/096317909X470690

Eberz, S., Becker, R., \& Antoni, C.H. (2011). Kohärenzerleben im Arbeitskontext: Ein nützliches Konstrukt für die $\mathrm{ABO}$-Psychologie? [Work-related sense of coherence - A useful construct for occupational psychology?]. Zeitschrift für Arbeits- und Organisationspsychologie, 55, 115-131. http://dx.doi.org/10.1026/0932-4089/ a000056

Edwards, J.R., \& Shipp, A.J. (2007). The relationship between person-environment fit and outcomes: An integrative theoretical framework. In C. Ostroff \& T.A. Judge (Eds.), Perspectives on organizational fit (pp. 209-258). San Francisco, CA: JosseyBass.

Eriksson, M., \& Lindström, B. (2006). Antonovsky's sense of coherence scale and the relation with health: A systematic review. Journal of Epidemiology and Community Health, 60, 376-381. http://dx.doi.org/10.1136/jech.2005.041616

Feldt, T. (1997). The role of sense of coherence in well-being at work: Analysis of main and moderator effects. Work \& Stress, 11, 134-147. http://dx.doi. org/10.1080/02678379708256830

Feldt, T., Kinnunen, U., \& Mauno, S. (2000). A mediational model of sense of coherence in the work context: A 1-year follow-up study. Journal of Organizational Behavior, 21, 461-476.

Feldt, T., Kivimäki, M., Rantala, A., \& Tolvanen, A. (2004). Sense of coherence and work characteristics: A cross-lagged structural equation model among managers.
Journal of Occupational and Organizational Psychology, 77, 323-342. http:// dx.doi.org/10.1348/0963179041752655

Frese, M. (1989). Gütekriterien zur Operationalisierung von sozialer Unterstützung am Arbeitsplatz [Criteria for operationalisation of social support at the workplace] Zeitschrift für Arbeitswissenschaften, 43, 112-121.

Gräser, S. (2003). Hochschule und Gesundheit: Salutogenese am Arbeitsplatz Universität. Lengerich, Germany: Pabst.

Hogh, A., \& Mikkelsen, E.G. (2005). Is sense of coherence a mediator or moderator of relationships between violence at work and stress reactions? Scandinavian Journal of Psychology, 46, 429-437. http://dx.doi.org/10.1111/j.1467-9450.2005.00474.x

Jacobshagen, N., Oehler, N., Stettler, E., Liechti, S., \& Semmer, N.K. (2008, November). Appreciation at work: Measurement and associations with well-being. Poster presented at the 8th Conference of the European Academy of Occupational Health Psychology, Valencia, Spain.

Kalimo, R., Pahkin, K., Mutanen, P., \& Toppinen-Tanner, S. (2003). Staying well or burning out at work: Work characteristics and personal resources as long-term predictors. Work \& Stress, 17, 109-122. http://dx.doi.org/10.1080/0267837031000149919

Kinman, G. (2008). Work stressors, health and sense of coherence in UK academic employees. Educational Psychology, 28, 823-835. http://dx.doi. org/10.1080/01443410802366298

Lazarus, R.S., \& Folkman, S. (1984). Stress, appraisal, and coping. New York, NY: Springer.
Muller, Y., \& Rothmann, S. (2009). Sense of coherence and employees' perceptions of helping and restraining factors in an organisation. SA Journal of Industria Psychology, 35(1), 10 pages. http://dx.doi.org/10.4102/sajip.v35i1.731

Pahkin, K., Väänänen, A., Koskinen, A., Bergbom, B., \& Kouvonen, A. (2011) Organizational change and employees) mental health: The protective role of sense of coherence. Journal of Occupational and Environmental Medicine, 53, 118-123. http://dx.doi.org/10.1097/JOM.0b013e318206f0cb

Podsakoff, P.M., MacKenzie, S.B., Lee, J.Y., \& Podsakoff, N.P. (2003). Common method biases in behavioral research: A critical review of the literature and recommended remedies. Journal of Applied Psychology, 88, 879-903. http:// dx.doi.org/10.1037/0021-9010.88.5.879

Preacher, K.J., \& Hayes, A.F. (2008). Asymptotic and resampling strategies for assessing and comparing indirect effects in multiple mediator models. Behavior Research Methods, 40, 879-891. http://dx.doi.org/10.3758/BRM.40.3.879

Schaufeli, W.B., Bakker, A.B., \& Salanova, M. (2006). The measurement of work engagement with a short questionnaire: A cross-national study. Educational and Psychological Measurement, 66, 701-716, http://dx.doi. org/10.1177/0013164405282471

Schmitt, N., \& Kuljanin, G. (2008). Measurement invariance: Review of practice and implications. Human Resource Management Review, 18, 210-222. http://dx.doi. org/10.1016/j.hrmr.2008.03.003

Seligman, M.E.P. (2008). Positive health. Applied Psychology: An International Review, 57, 3-18. http://dx.doi.org/10.1111/j.1464-0597.2008.00351.x

Semmer, N.K., Zapf, D. \& Dunckel, H. (1995). Assessing stress at work: A framework and an instrument. In O. Svane \& C. Johansen (Eds.), Work and health: Scientific basis of progress in the working environment (pp. 105-113). Luxembourg: Office for Official Publications of the European Communities.

Semmer, N.K., Zapf, D., \& Dunckel, H. (1999). Instrument zur stressbezogenen Tätigkeitsanalyse: ISTA. In H. Dunckel (Ed.), Handbuch psychologischer Arbeitsanalyseverfahren: Ein praxisorientierter Überblick (pp. 179-204). Zurich, Switzerland: vdf Hochschulverlag

Udris, I., \& Rimann, M. (1999). SAA und SALSA: Zwei Fragebögen zur subjektiven Arbeitsanalyse. In H. Dunckel (Ed.), Handbuch psychologischer Arbeitsanalyseverfahren. Ein praxisorientierter Überblick (pp. 397-419). Zurich, Switzerland: vdf Hochschulverlag.

Van der Colff, J.J., \& Rothmann, S. (2009). Occupational stress, sense of coherence, coping, burnout and work engagement of registered nurses in South Africa. SA Journal of Industrial Psychology, 35(1), 10 pages. http://dx.doi.org/10.4102/sajip. v35i1.423

Vogt, K., Jenny, G.J., Füllemann, D., Inauen, A., \& Bauer, G.F. (2012, August). Workrelated sense of coherence as a higher-order indicator of salutogenic working conditions. Paper presented at Health Promotion Research - An International conditions. Paper presented

Xanthopoulou, D., Bakker, A.B., Demerouti, E., \& Schaufeli, W.B. (2007). The role of personal resources in the job demands-resources model. International Journal of Stress Management, 14, 121-141. http://dx.doi.org/10.1037/10725245.14.2.121 